\title{
Serum proteins in ulcerative colitis: electrophoretic patterns in the inferior mesenteric artery and vein
}

\author{
F. T. de DOMBAL \\ From the University Department of Surgery, The General Infirmary at Leeds
}

EDITORIAL COMMENT. These studies suggest that there is a local production or release of alpha 2 globulins and a fixation or destruction of gamma globulin by the diseased colon.

Previous studies have indicated that in patients with severe attacks of ulcerative colitis, changes occur in the levels of the serum proteins. These changes consist principally of a fall in the serum albumin level, and a rise in the level of the alpha 2 globulins (Bicks, Kirsner, and Palmer, 1959; Brooke, Dykes, and Walker 1961; Soergel and Ingelfinger, 1961). Furthermore attacks of ulcerative colitis which fail to respond to conservative treatment are almost invariably accompanied by a low level of serum gamma globulin (de Dombal, 1967).

However, these studies have done nothing to indicate the mechanisms responsible for the observed serum protein changes. In further investigations, therefore, the electrophoretic patterns have been compared in samples of blood removed at operation from the inferior mesenteric artery and the inferior mesenteric vein. Nineteen patients have been thus studied: a group of 10 patients with severe ulcerative colitis and a control group of nine patients with rectal or colonic cancer.

\section{CLINICAL MATERIAL AND METHODS}

Between 1 March and 31 August 1966, a group of 10 patients were brought to radical surgery because of severe attacks of ulcerative colitis which were unresponsive to conservative treatment. At operation, immediately after the abdomen was opened, the inferior mesenteric vessels were identified and isolated. A sample of blood was then removed from the inferior mesenteric artery and a further sample from the inferior mesenteric vein. Both of these vessels were then ligated and divided in the usual manner.

The samples of blood were then centrifuged and the serum was pipetted off. Total protein and albumin levels were determined using a routine Biuret method; and electrophoresis was carried out for each of the two samples using cellulose acetate membrane. Results have been expressed as g. $\%$ and each result is the mean of two entirely separate estimations which were performed on each individual sample.
A further group of nine control patients with colonic cancer were studied; in seven of these patients blood was removed from the inferior mesenteric artery and vein and analysed by the same method. In the remaining two patients with a right-sided carcinoma of the colon, blood was removed from the appropriate right colic artery and vein and was again analysed in an identical manner.

\section{FINDINGS}

The overall findings of this study are shown in Figure 1. This figure compares the arterial and venous concentrations of each protein fraction, both in the case of the control patients with colonic cancer, and in the case of the patients with ulcerative colitis. It will be seen that the arterial and venous concentrations of the various protein fractions are virtually identical in each of the nine patients with carcinoma. However, in each of the 10 patients with ulcerative colitis a well-marked rise in the venous sample in the level of the alpha 2 globulin

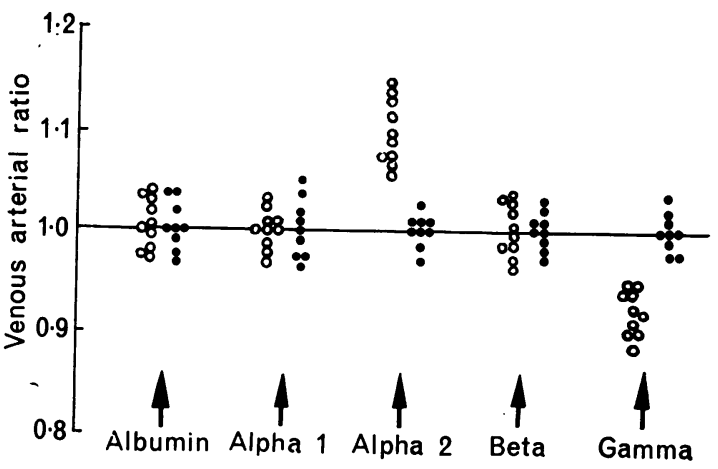

FIG. 1. Comparison of serum protein levels in the inferior mesenteric artery and vein in 10 patients with ulcerative colitis (white circles) and nine patients with colonic cancer (black dots). 
fraction was shown. It is noticeable also that in each of the 10 patients with colitis, less gamma globulin was found in the venous sample than in the arterial sample.

Figures 2 and 3 indicate that these arteriovenous differences are almost certainly significant. Figure 2 deals with the alpha 2 globulins and shows the standard error of estimation of this fraction (worked out on the basis of the nine control cases with colonic cancer) to be in the region of $\pm 0.01 \mathrm{~g} . \%$. It can be seen that in all 10 of the colitis patients the venous alpha 2 globulin concentration exceeds the arterial concentration by on average around 10

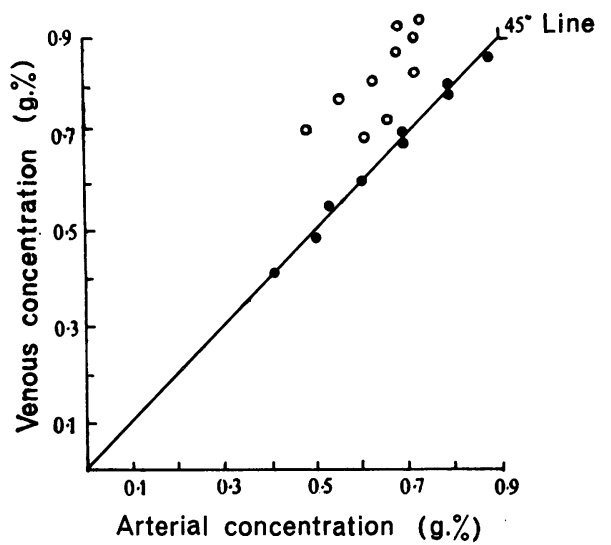

FIG. 2. Comparison of arterial and venous concentrations of alpha 2 globulins in 10 colitic patients (white circles) and nine patients with colonic cancer (black dots). (Regression line for control cancer patients approximates to $45^{\circ}$ line: $x=1.022 \mathrm{y}+0.019 ; r=0.998 ;$ s.e.e. $= \pm$ $0.01 \mathrm{~g} . \%$.)

times the standard error of estimation. It may be concluded from Fig. 2, therefore, that the rise in the venous alpha 2 globulin concentration in patients with ulcerative colitis is highly significant.

Figure 3 deals with the gamma globulins. The standard error of estimation in calculating this fraction in the nine control colonic cancer patients is in the region of $\pm 0.02 \mathrm{~g} . \%$. A glance at Fig. 3 indicates that all 10 colitic patients had an arterial concentration which exceeded the venous concentration, on average by four or five times the standard error of estimation of this fraction. It may be concluded, therefore, from Fig. 3 that the fall in the venous gamma globulin level is also highly significant.

\section{DISCUSSION}

As a result of several surveys over the past decade, it is now widely accepted that serum protein changes occur in patients with ulcerative colitis. The changes which are noted in the systemic serum proteins during severe attacks are principally threefold: a fall in the serum albumin level, a rise in the alpha 2 globulin fraction, and a fall in the level of gamma globulin (Bicks et al., 1959; Brooke et al., 1961; Soergel and Ingelfinger, 1961; de Dombal, 1967).

The nature of the mechanisms which are responsible for bringing about these serum protein changes has previously been far from clear. Nevertheless, data from the present study provide some indication of the mechanism by which two of the observed changes are brought about, namely, the rise in the

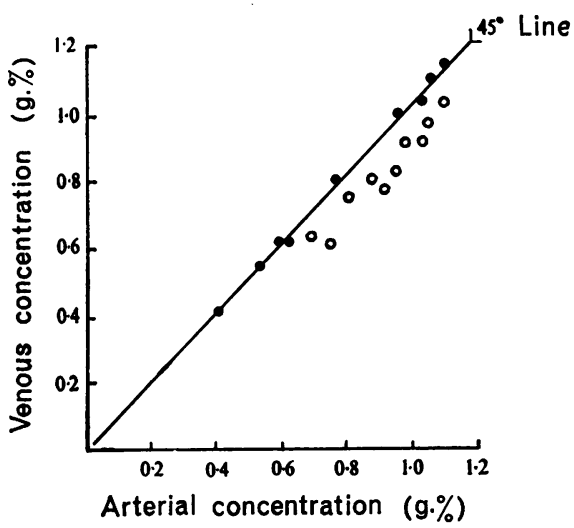

FIG. 3. Comparison of arterial and venous concentrations of gamma globulins in 10 colitic patients (white circles) and nine patients with colonic cancer (black dots). (Regression line for control cancer patients again approximates to the $45^{\circ}$ line: $x=1.036 y+0.021 ; r=$ 0.997 ; s.e.e. $= \pm 0.02 \mathrm{~g} . \%$.)

systemic alpha 2 globulin level, and the concomitant fall in the gamma globulin level.

ALPHA 2 globulins The data from the present study indicate a significant rise in the alpha 2 globulin concentration in the venous return from the inflamed colon, and such a rise was not observed in any of the nine control cases of carcinoma. If the concentration of alpha 2 globulins is higher in the venous return from the colon than in the arterial blood supplying it, then several possibilities are immediately apparent.

It could possibly be argued that the rise in the venous sample of the alpha 2 globulins was due merely to haemoconcentration. This seems extremely unlikely, since the other globulin fractions, and the albumin level, do not show a similar rise in the venous sample. In addition, concomitant studies showed virtually no difference in the haemoglobin and P.V.C. level in the inferior mesenteric artery 
and vein of these patients, indicating that no haemoconcentration was taking place.

Recent studies by Millar and Brooke (1966) have indicated that in patients with ulcerative colitis absorption of macromolecules takes place across the damaged colonic mucosa; and it could also be argued that this absorption of macromolecules was responsible for the rise in the venous alpha 2 concentration. Such absorption of macromolecules may well be taking place; but clearly this cannot explain the selective rise in the alpha 2 globulin concentration in the vein. Therefore, some additional mechanism must be at work, and it is dfficult to avoid the conclusion that in patients with ulcerative colitis, the systemic alpha 2 globulin concentration rises because of the local production or release of these globulins.

The inflamed colon of ulcerative colitis is perhaps a unique organ for study, since it possesses the important advantage of being a single widely inflamed organ situated at the end of a long vascular pedicle. However, this does not mean to say that the local production of alpha 2 globulins is necessarily restricted to patients with ulcerative colitis. A rise in the systemic alpha 2 globulin concentration has been noted in many other inflammatory and neoplastic diseases (Hoch-Ligeti, Irvine, and Spinkle, 1953; Neumayer Perger, Schinko, and Tschabitscher, 1956; Peterman, 1960; Heim and Lane, 1964; Atwell, Duthie, and Goligher, 1965; McCathie, Owen, and Macpherson, 1966). Glycoproteins form an important fraction of the alpha 2 globulins, and it is of interest to note that a similar rise in these proteins has also been widely noted (Catchpole, 1950; Almquist and Lausing, 1957; Burnett, McAllister, and Shields 1963; Shields, McAllister, and Burnett 1963).

In view of the data from these previous studies, it now seems reasonable to argue that the observed rise in the systemic alpha 2 globulins in many other conditions may also be due to the local production or release of these proteins and not to any generalized response on the part of the body.

It is interesting that in the present series of patients, a high venous alpha 2 globulin level was not found in any of the nine patients with colonic cancer. In most cases this was undoubtedly due to a dilutional effect, since blood was removed from the inferior mesenteric vein at a considerable distance from the colonic cancer. In the two patients with right-sided colonic cancer, however, blood was removed from a vein close to the lesion. No large rise was noted in the venous alpha 2 globulin level in either of these samples but is interesting that both showed a rise in the alpha 1 globulin concentration in the venous sample.
GAMMA GLOBULINS If part of the serum gamma globulin is entering the colon and not leaving it, two possibilities are immediately apparent. First there could be a selective loss of gamma globulin in the faeces of patients with ulcerative colitis. This seems unlikely, for preliminary observations on a small series of patients would appear to confirm the findings of Soergel and Ingelfinger (1964), who have indicated that the rectal mucus of patients with ulcerative colitis is little different from the rectal mucus of control patients. Certainly no selective loss of gamma globulin seems to be taking place.

The second intriguing possibility is that gamma globulin is being bound or destroyed in the colon. Such a possibility has already been suggested by experiments in vitro (Broberger and Perlmann, 1959), and the present study would appear to provide confirmatory in vivo evidence in favour of the findings of these workers in this respect.

Broberger and Perlmann were, however, unable to demonstrate any cytotoxic effect of the antibody which was bound to the colon in the in vitro studies which they reported. Indeed, further recent studies have shown a complete lack of correlation between the prevalence of autoantibody and the clinical pattern of ulcerative colitis, and have suggested that the tissue damage may well be caused by sensitive white blood cells rather than by circulating antibodies (Perlmann and Broberger, 1963; Harrison, 1965; Wright and Truelove, 1966).

The present series of studies again appears to confirm these findings, in that the response of the patient to conservative therapy appears to be directly related to the amount of gamma globulin available in the serum (de Dombal, 1967). It does seem more likely, therefore, that the gamma globulin fixation in the colon takes place as part of a defence mechanism, and may well be the result of the initial attack rather than its immediate cause.

MECHANISMS RESPONSIBLE FOR PROTEIN CHANGES Thus the present study enables a tentative scheme to be put forward to explain the observed serum protein changes in patients with ulcerative colitis. The data from the present study suggest that the sequence of events which takes place in patients with an attack of ulcerative colitis is as follows:

1 During the course of a localized attack upon the colonic mucosa, alpha 2 globulins are released locally, and pass into the systemic circulation via the inferior mesenteric vein.

2 As a sequel to this attack upon the colonic mucosa, there is a reaction by the immune systems of the body, which results in an increased production of gamma globulin. 
3 The gamma globulin thus produced is liberated into the systemic circulation where some of it passes via the inferior mesenteric artery to the colon.

4 The gamma globulin having reached the colon is either destroyed or is fixed there.

Such a tentative scheme may well be open to severe criticism because many of the details by which these mechanisms are brought about are as yet unknown. However, on the basis of the present data, this scheme does seem to be the mechanism most likely to be responsible for the observed serum protein changes in severe attacks of ulcerative colitis.

\section{SUMMARY}

The serum protein levels in the inferior mesenteric artery and the inferior mesenteric vein have been compared in 19 patients who came to operation, 10 patients with severe ulcerative colitis, and nine control patients with colonic cancer.

In all 10 of the patients with ulcerative colitis there was a significant rise in the level of the alpha 2 globulins in the inferior mesenteric vein and a concomitant significant fall in the venous gamma globulin concentration. No such changes were observed in the control patients with colonic cancer.

It is suggested that these observations are the result of two specific mechanisms in patients with ulcerative colitis, namely, the local production or release of alpha 2 globulins, and the fixation or destruction of gamma globulins in the inflamed colon.

I am grateful to Professor J. C. Goligher for his encouragement and advice, for permission to study his patients, and for obtaining many of the blood samples. Other samples were kindly obtained by Mr. N. G. Graham. I am grateful also to Mrs. R. Bulmer for her technical assistance.

\section{REFERENCES}

Almquist, P. O., and Lausing, E. (1957). A study of serum glycoproteins in cancer. Scand. J. clin. Lab. Invest., 9, 179-189.

Atwell, J. D., Duthie, H. L., and Goligher, J. C. (1965). The outcome of Crohn's disease. Brit. J. Surg., 52, 966-972.

Bicks, R. O., Kirsner, J. B., and Palmer, W. L. (1959). Serum proteins in ulcerative colitis. I. Electrophoretic patterns in active disease. Gastroenterology, 37, 256-262.

Broberger, O., and Perlmann, P. (1959). Autoantibodies in human ulcerative colitis. J. exp. Med., 110, 657-674.

Brooke, B. N., Dykes, P. W., and Walker, F. C. (1961). A study of liver disorder in ulcerative colitis. Post grad. med.J., 37, 245-251.

Burnett, W., McAllister, R. A., and Shields, R. (1963). The use of serum glycoprotein levels in the selection of patients with advanced breast cancer for endocrine surgery. Scot. med. J., 8, 197-203.

Catchpole, H. R. (1950). Serum and tissue glycoproteins in mice bearing transplantable tumors. Proc. Soc. exp. Biol. (N.Y.), 75, $221-223$.

de Dombal, F. T. (1967). Serum protein levels in severe attacks of ulcerative colitis. In preparation.

Harrison, W. J. (1965) Autoantibodies against intestinal and gastric mucous cells in ulcerative colitis. Lancet, 1, 1346-1350.

Heim, W. G., and Lane, P. H. (1964). Appearance of slow alpha 2globulin during the inflammatory response of the rat. Nature (Lond.), 203, 1077-1078.

Hoch-Ligeti, E., Irvine, K., and Spinkle, E. P. (1953). Investigation of serum protein patterns in patients undergoing operation. Proc. Soc. exp. Biol. (N.Y.)., 84, 707-710.

McCathie, M., Owen, J. A., and MacPherson, A. I. S. (1966). The effect of surgery on levels of some plasma proteins. Scot. med. J., 11, 83-88.

Millar, D. M., and Brooke, B. N. (1966). A method of serial portal venous sampling. Gut, 7, 717 .

Neumayer, E., Perger, F., Schinko, H., and Tschabitscher, P. (1956). Das Serumeiweissbild bei der multiplen Sklerose. Wien. $Z$. Nervenheilk., 13, 46-64.

Perlmann, P., and Broberger, O. (1963). In vitro studies of ulcerative colitis. II. Cytotoxic action of white blood cells from patients on human fetal colon cells. J. exp. Med., 117, 717-733.

Peterman, M. L. (1960). The Plasma Proteins. vol. t2. Academic Press, New York.

Shields, R., McAllister, R. A., and Burnett, W. (1963). Evaluation of serum glycoproteins in the differential diagnosis of jaundice. Scot. med. J., 8, 185-196.

Soergel, K. H., and Ingelfinger, F. J. (1961). Proteins in serum and rectal mucus of patients with ulcerative colitis. Gastroenterology, 40, 37-46.

,,$--(1964)$. Composition of rectal mucus in normal subjects and patients with ulcerative colitis. Ibid., 47, 610-616.

Wright, R., and Truelove, S. C. (1966). Auto-immune reactions in ulcerative colitis. Gut, 7, 32-40. 